\title{
OsTCTP, encoding a translationally controlled tumor protein, plays an important role in mercury tolerance in rice
}

\author{
Zhan Qi Wang ${ }^{1}$, Ge Zi Li', Qiao Qiao Gong ${ }^{1}$, Gui Xin Li ${ }^{2}$ and Shao Jian Zheng ${ }^{1 *}$
}

\begin{abstract}
Background: Mercury $(\mathrm{Hg})$ is not only a threat to public health but also a growth risk factor to plants, as it is readily accumulated by higher plants. Accumulation of $\mathrm{Hg}$ in plants disrupts many cellular-level functions and inhibits growth and development; however, the detoxification and tolerance mechanisms of plants to $\mathrm{Hg}$ stress are still not fully understood. Exposure to toxic $\mathrm{Hg}$ also occurs in some crops cultivated under anoxic conditions, such as rice (Oryza sativa L.), a model organism and one of the most important cultivated plants worldwide. In this study, we functionally characterized a rice translationally controlled tumor protein gene (Os11g43900, OsTCTP) involved in Hg stress tolerance.

Results: OSTCTP was ubiquitously expressed in all examined plant tissues, especially in actively dividing and differentiating tissues, such as roots and nodes. OsTCTP was found to localize both the cytosol and the nucleus. OsTCTP was induced by mercuric chloride, cupric sulfate, abscisic acid, and hydrogen peroxide at the protein level in a time-dependent manner. Overexpression of OSTCTP potentiated the activities of several antioxidant enzymes, reduced the $\mathrm{Hg}$-induced $\mathrm{H}_{2} \mathrm{O}_{2}$ levels, and promoted $\mathrm{Hg}$ tolerance in rice, whereas knockdown of OsTCTP produced opposite effects. And overexpression of OsTCTP did not prevent $\mathrm{Hg}$ absorption and accumulation in rice. We also demonstrated that Asn 48 and Asn 97 of OsTCTP amino acids were not the potential N-glycosylation sites.

Conclusions: Our results suggest that OSTCTP is capable of decreasing the Hg-induced reactive oxygen species (ROS), therefore, reducing the damage of ROS and enhancing the tolerance of rice plants to Hg stress. Thus, OsTCTP is a valuable gene for genetic engineering to improve rice performance under $\mathrm{Hg}$ contaminated paddy soils.
\end{abstract}

Keywords: Oryza sativa L, Mercury stress, Antioxidant enzyme, Hydrogen peroxide levels, N-glycosylation

\section{Background}

Mercury $(\mathrm{Hg})$ is deadly toxic to humans and ecosystems, which is considered as a global pollutant because it is highly mobile and extremely persistent in the environment [1]. It is not only a threat to public health [2] but also a growth risk factor to plants [3], as it is readily accumulated by higher plants [4-6]. As a phytotoxic metal, $\mathrm{Hg}$ has wideranging adverse effects on the physiological activities of plants, such as prevention of water and mineral nutrient uptake $[7,8]$ and inhibition of photosynthesis $[9,10]$. Furthermore, mercuric ions react specifically with sulfhydryl groups of proteins and other biomolecules and induce the

\footnotetext{
* Correspondence: sjzheng@zju.edu.cn

${ }^{1}$ State Key Laboratory of Plant Physiology and Biochemistry, College of Life Sciences, Zhejiang University, Hangzhou 310058, China

Full list of author information is available at the end of the article
}

Fenton reaction, resulting in oxidative stress, lipid peroxidation [11-13], cell damage and signaling disruption in plants $[3,14]$. Exposure to toxic $\mathrm{Hg}$ also occurs in some crops cultivated under anoxic conditions, such as rice $[15,16]$. Recent studies have demonstrated that rice intake is the major pathway for human exposure to $\mathrm{Hg}$ in inland China $[17,18]$. So, it is of immense importance to elucidate the detoxification and tolerance mechanisms of rice plants to $\mathrm{Hg}$ and consequently optimize rice performance under $\mathrm{Hg}$ contaminated paddy soils.

The translationally controlled tumor protein (TCTP), also variously known as Q23 [19], P21 [20], P23 [21], IgE-dependent histamine-releasing factor (HRF) [22], and fortilin [23], is ubiquitously found in all eukaryotes. As implicated in its name, TCTP is regulated at both translational and posttranslational levels in response to a 
wide range of extracellular signals and conditions and exerts diverse functions in various cellular processes such as cell growth, proliferation, cell cycle progression, DNA repair, malignant transformation, anti-apoptosis as well as protection against various cellular stresses and other immunological functions [24-26]. In Arabidopsis, TCTP has been shown to be an important growth regulator and expressed throughout plant tissues and developmental stages with increased expression in meristematic and expanding cells [27]. Knockdown of AtTCTP by RNA interference slows vegetative growth and exhibits severe dwarf phenotype due to a reduction of cell numbers, whereas homologous tctp plants (T-DNA insertion lines) are embryonic lethal [25]. Overexpression of AtTCTP enhances drought tolerance with rapid ABA-induced stomatal closure [28]. Moreover, plant TCTP protein is also proposed to have a role in long-distance movement of phloem proteins and in regulating the hypersensitive response $[29,30]$. These published results reveal that TCTP not only regulates organismal growth but also asserts plant specific functions.

Previously, through a 2-D gel analysis, OsTCTP was presumed to participate in the $\mathrm{Hg}$ tolerance of rice at the protein level [31]. However, the functional analysis of OsTCTP in rice is still very scanty, and the molecular and physiological mechanisms of OsTCTP in rice $\mathrm{Hg}$ tolerance are still not fully understood. Here, we reported the isolation and functional characterization of OsTCTP (Os11g43900), which was induced under Hg stress condition in rice [31]. The OsTCTP is shown to be more highly expressed in physiologically active and proliferating tissues as would be expected for a component of the target of rapamycin (TOR) pathway. Analysis of a TDNA insertion line in the promoter region demonstrated that transcriptional knockdown of OsTCTP caused compensation in protein abundance due to the translational regulation. Overexpression of OsTCTP potentiated the activities of several antioxidant enzymes, whereas knockdown of OsTCTP aborted the antioxidant system and increased the $\mathrm{Hg}$-induced $\mathrm{H}_{2} \mathrm{O}_{2}$. Our results suggested that OsTCTP confers tolerance to $\mathrm{Hg}$ stress possibly through the regulation of ROS and their scavengers.

\section{Results}

OsTCTP is a single-copy gene with two differentially spliced transcripts but only one transcript can be translated

Reverse transcription-polymerase chain reaction (RT-PCR) with a pair of primers spanning an exon junction of OsTCTP gene amplified two cDNA fragments (OsTCTPa and $O s T C T P b)$ from the rice root and shoot RNA samples (Figure 1A). To determine if these two fragments were derived from alternative splicing of a single gene, southern blot hybridization was performed with a probe covering an identical region of both OsTCTPa and OsTCTPb. One strongly hybridizing band was detected in each of the three digestions (EcoRI, HindIII and XhoI) of rice genomic DNA (Figure 1B). Genomic PCR with a pair of primers covering the differentiated region also gave rise to a single band (Figure 1C). Therefore, OsTCTPa and OsTCTPb most likely resulted from the alternative splicing of a single OsTCTP gene in rice plants. Sequence alignments showed that OsTCTPb was 190 bp longer than OsTCTPa and encoded a putative truncated protein due to an open reading frame shift (Additional file 1: Figure S1). Interestingly, in both root and shoot tissues, OsTCTPa was the predominant isoform of OsTCTP transcripts. This is consistent with the previous report showing that there are usually several different cDNAs in many plant species [27].

To determine if these two transcripts could be translated into mature proteins, CDSs of both OsTCTPa and $O s T C T P b$ were subcloned into a binary expression vector pCUN1301, respectively, which were driven by a constructive maize ubiquitin 1 promoter (Figure 2A). Transgenic plants were generated by introducing the constructs into the japonica rice cultivar 'Nippobare' by Agrobacterium tumefaciens-mediated transformation [32]. Thirty-two independent OsTCTPa-OX transgenic plants and 11 independent $O s T C T P b$-OX transgenic plants were generated (T0 generation), each containing one to several copies of the transgene, as confirmed by southern blot analysis (Additional file 1: Figures S2B and S3). We then tested GUS expression in OsTCTPb-OX T0 plants and eight of them showed the GUS activity (Figure 2B). The eight OsTCTPb-OX T0 plants showing GUS activity were then subjected to western blot analysis to investigate the accumulation of the OsTCTP protein. This revealed that no OsTCTPb protein was detected in neither wild-type (WT) under the control of the native promoter nor the transgenic plants under the control of the constructive promoter (Figure 2C). Taken together, these results strongly indicated that OsTCTP is a single-copy gene with two differentially spliced transcripts but only OsTCTPa transcript can be translated into mature protein. So, in the following text, OsTCTP refers to the translational product of OsTCTPa gene.

\section{OsTCTP is a typical TCTP protein}

Searching of protein databases for sequences similar to well-characterized TCTPs (human, Drosophila and yeast) reveals TCTP homologs in a large number of plant species. Protein sequence comparison of plant and non-plant TCTPs showed amino acid identities in the range of $40 \%$ and similarities of $\sim 60 \%$ using the Point Accepted Mutation (PAM) matrix [33]. InterProScan [34] analysis showed that OsTCTP has two typical TCTP domains TCTP1 (45-55) and TCTP2 (125-147) 

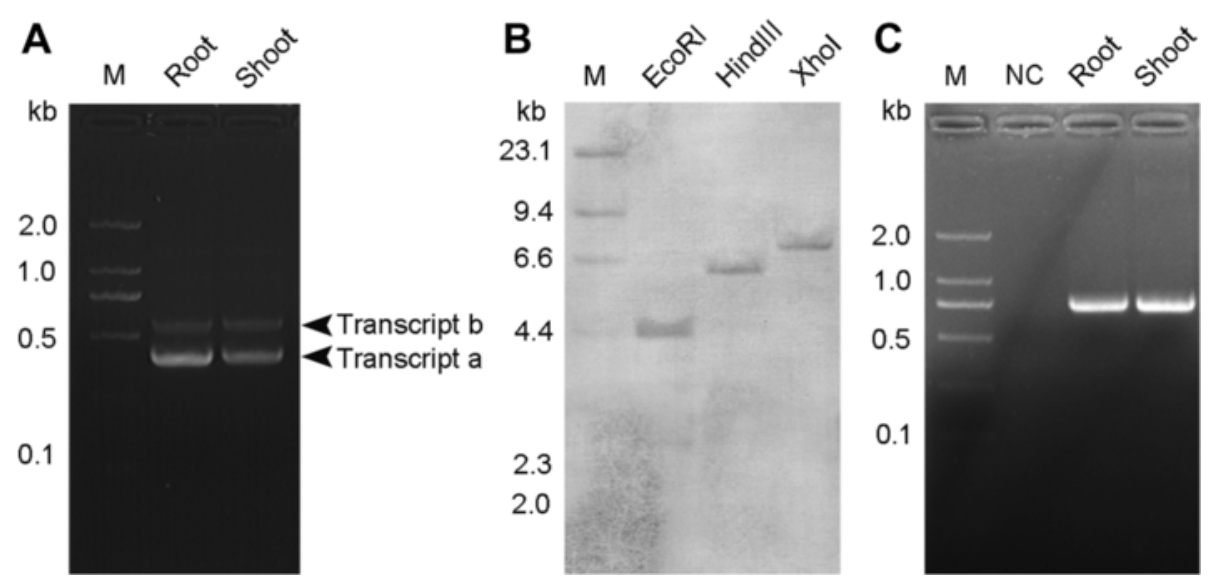

Figure 1 Genomic organization and alternative splicing of OSTCTP. (A) RT-PCR analysis using a primer pair covering the differentiated regions of the OsTCTPa and OsTCTPb cDNAs. The root and shoot mRNAs from cv. 'Nipponbare' were used for RT-PCR. (B) Southern blot analysis of the OSTCTP gene. Total DNA from cv. 'Nipponbare' (30 $\mathrm{g}$ for each lane) was digested individually with EcoRl, Hindlll and Xhol and hybridized with a gene-specific probe covering the region from nucleotide 513 to the $3^{\prime}$ end of the OsTCTPa CDNA. (C) Genomic PCR analysis using two primers covering the differentiated regions of the OsTCTPa and OsTCTPb. The leaf DNA from cv. 'Nipponbare' was used for genomic PCR. M, DNA size markers.

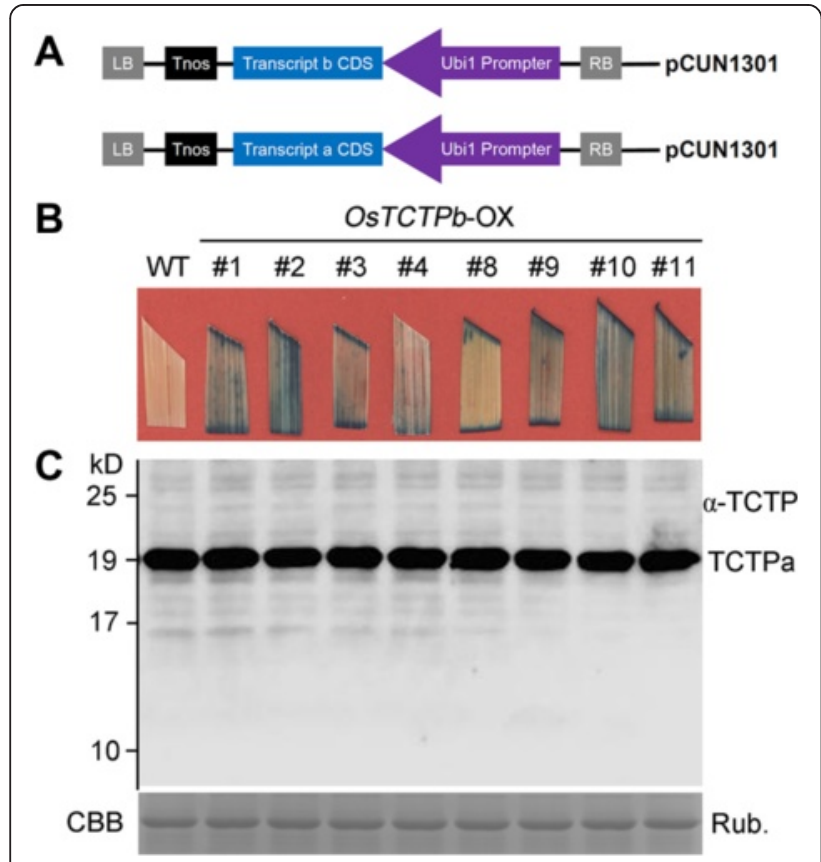

Figure 2 OSTCTP expression patterns in transgenic rice plants. (A) Structure of constructs for rice transformation. The overexpression constructs (OsTCTPa and OsTCTPb) were developed under the control of the Ubi1 promoter and nopaline synthase (Nos) terminator cassette. (B) GUS staining of OsTCTPb overexpression transgenic rice plants. (C) Western blot analysis of OsTCTP protein from transgenic plants using an antibody against rice OsTCTP. Equal amounts $(20 \mu \mathrm{g})$ were loaded to each lane and confirmed by coomassie brilliant blue (CBB) staining of Rubisco (bottom). The experiments were repeated for three times with similar results.
(Figure 3A). This comparative analysis indicated that OsTCTP is a TCTP protein at the primary structure of protein. In parallel, we used homology modeling to obtain a 3D-structure prediction for the OsTCTP protein to investigate the possibility that it might have a similar function as TCTP in other organisms. This model showed high similarity to the known structure of the human TCTP protein with a nearly identical spatial organization of $\alpha$-helices, $\beta$ sheets, and an unstructured loop (Figure 3B,C). Furthermore, phylogenetic analysis between OsTCTP and its 15 homologs indicated that OsTCTP is closely related to the wheat TCTP protein (Figure 3D). Based on the data presented in the phylogenetic tree, the TCTP family was divided into two groups. Those from plants such as Arabidopsis thaliana, maize (Zea mays) and wheat (Triticum aestivum) form one cluster, and those from non-plants form the other cluster. The OsTCTP is expectedly mapped to the plants cluster. This result indicated that the phylogenetic clustering of TCTP sequences is almost consistent with the accepted phylogeny of eukaryotes. From these results, it is clear that the OsTCTP is a typical TCTP at both protein and evolution levels.

\section{OsTCTP gene is regulated at the translational level}

It has been shown that TCTP genes are regulated at the translational level in animals [24,35]. To determine whether the synthesis of OsTCTP protein is also regulated at the translational level in rice, we examined the expression patterns of OsTCTP by mutant analysis. A mutant line of OsTCTP in the background of Dongjin, ostctp, with a T-DNA inserted in the promoter region (Figure 4A), was obtained from the Rice T-DNA Insertion Sequence Database (http://cbi.khu.ac.kr) [36]. After being confirmed for the T-DNA insertion site as 


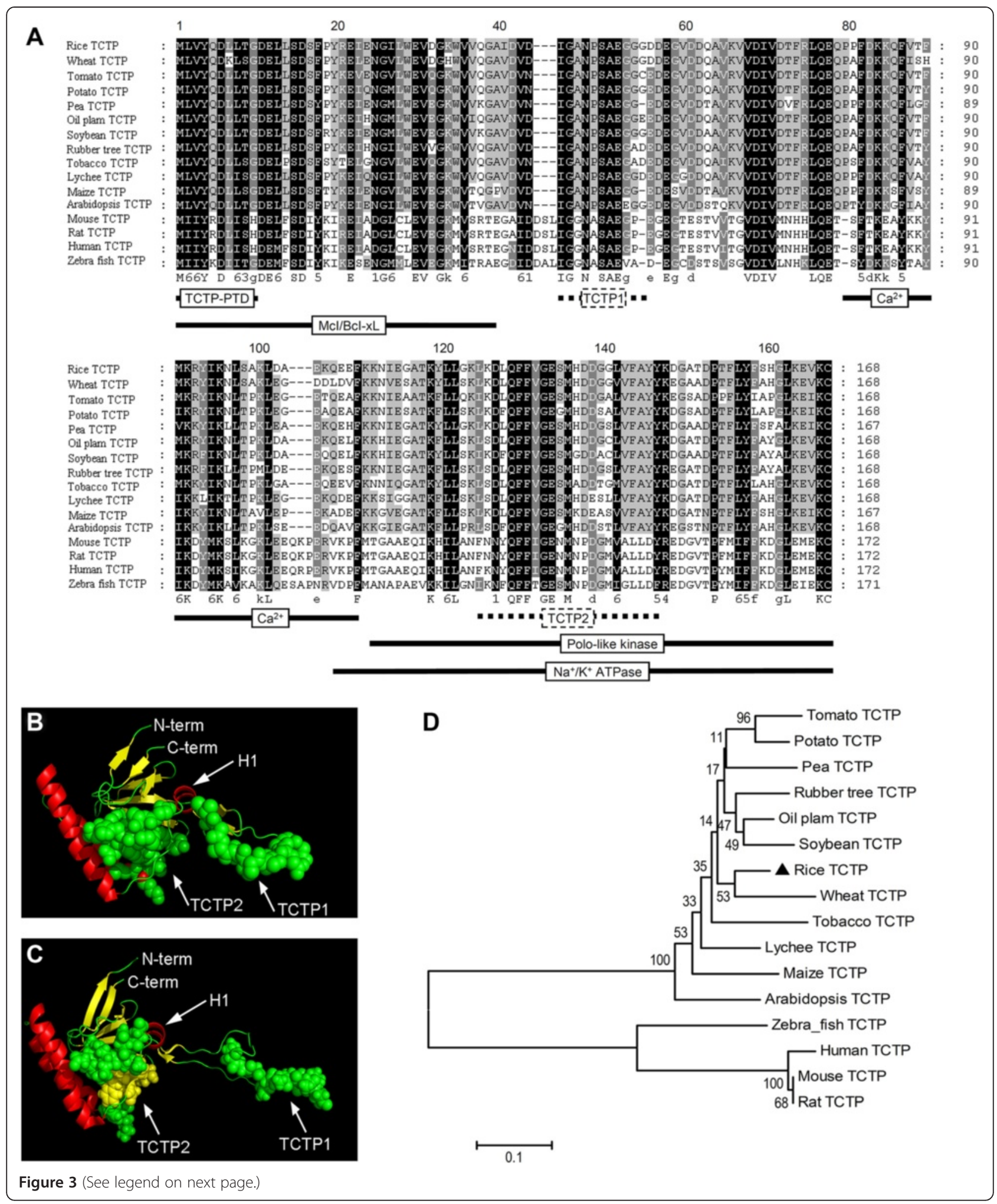




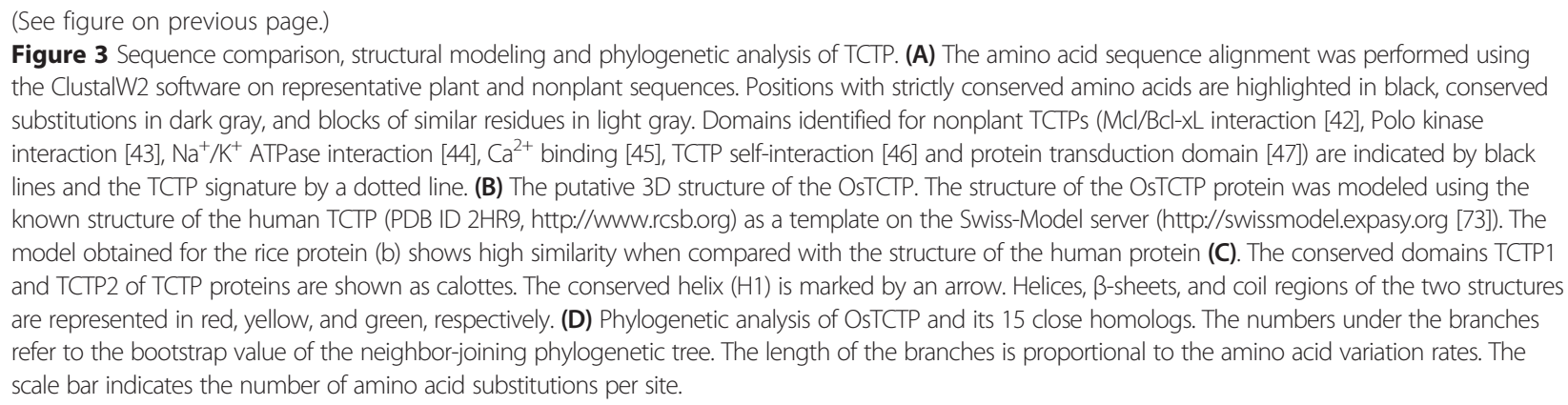

described previously [37], homozygous and heterozygous mutant plants (Figure 4B) were used for further analysis. Firstly, we examined the mRNA levels in the ostctp by qRT-PCR analysis. Notably, compared to the wild-type plants, it was down by approximately $10 \%$ to $30 \%$ in heterozygous (\#3 and \#4) and homozygous (\#1 and \#2) mutant plants, respectively (Figure $4 \mathrm{C}$ ), indicating that the expression of OsTCTP was interrupted at the transcriptional level in the mutant plants. And then, we checked the OsTCTP protein level in wild-type and mutant rice plants using the western blot. However, the data showed that the accumulation of OsTCTP protein was higher in mutant plants than that in the wild-type rice plants, especially in the homozygous mutant plants (\#1 and \#2, Figure 4D). These results indicated that OsTCTP gene is regulated at translational level in rice.

\section{Expression pattern and subcellular localization of OsTCTP}

To gain insight into TCTP function in rice plants, we investigated its expression pattern in a range of tissues by qRTPCR and western blot analyses. qRT-PCR analysis revealed that OsTCTP was expressed in all analyzed tissues (leaves, leaf sheaths, nodes, roots, inflorescences, and seeds) and predominantly expressed in leaf sheaths, nodes, roots and inflorescences (Figure 5A). Consistent with the results of qRT-PCR analysis, strong immunoblot signals were observed in leaf sheaths, nodes, roots, and inflorescences (Figure 5B), suggesting that OsTCTP is ubiquitously expressed in all examined plant tissues, especially in actively dividing and differentiating tissue types, such as roots and nodes.

To gain insight into further function of OsTCTP in rice plants, we determined its subcellular localization by translationally fusing full-length OsTCTP to the Nterminal of the green fluorescent protein (GFP) and expressing the chimeric protein under the control of the CaM35S promoter. Onion (Allium cepa) epidermal cells transiently expressing the GFP without OsTCTP showed signals throughout cells (Figure 6A). The fluorescence signal from OsTCTP-GFP fusion protein was observed both in the cytosol and nucleus (Figure 6B), and in the plasmolysed cells, the fluorescence of OsTCTP-GFP was still observed both in the cytosol and the nucleus
(Figure 6C). These results suggested that OsTCTP has dual localization and is consistent with its multifunctions in different biochemical reactions.

\section{Induction of OsTCTP protein accumulation by $\mathrm{Hg}, \mathrm{Cu}$, $A B A$, and $\mathrm{H}_{2} \mathrm{O}_{2}$ in rice}

Previous reports have shown that TCTPs have diverse roles in response to various stresses and some plant hormones $[24,27,35]$. To examine the role of OsTCTP, we investigated its time-dependent accumulation patterns under different stresses by western blot analysis. As shown in Figure 7, the OsTCTP protein accumulated in seedlings within 3 hours following $\mathrm{Hg}, \mathrm{Cu}$, and $\mathrm{ABA}$ treatments (Figure 7A-C). In contrast, the accumulation of OsTCTP protein arosed after 12 hours and then increased strongly over 48 hours of $\mathrm{H}_{2} \mathrm{O}_{2}$ stress treatment (Figure 7D). There was no visible accumulation of OsTCTP protein in seedlings treated with $\mathrm{H}_{2} \mathrm{O}$ only (Figure 7E). The protein level of OsTCTP was slightly accumulated under the $\mathrm{NaCl}$ stress and mechanical wound (Additional file 1: Figure S4A,B). However, the OsTCTP accumulation profile was not affected by PEG, SA, JA, and NAA treatments (Additional file 1: Figure S4C-E). These results revealed that OsTCTP is likely involved in some abiotic stress responses in rice plants.

\section{Phenotypic analysis of OsTCTP-OX and OsTCTP-RNAi transgenic plants}

To analyze the function of OSTCTP in rice, we constitutively increased or suppressed the expression of OsTCTP in transgenic rice plants. The transgenic lines were generated by introducing the overexpression construct (OsTCTP$\mathrm{OX}$ ) or the double-stranded RNA interference construct (OsTCTP-RNAi) into wild type of cv. 'Nipponbare'. Thirtytwo independent overexpression lines were generated using the OSTCTP-OX construct. Western blot analysis indicated that 28 lines showed high constitutive expression in the OsTCTP-OX transgenic plants (Additional file 1: Figure S2A) and 22 of them were selected to analyze by southern blot and 5 OsTCTP-OX lines contained a single-copy insertion (Additional file 1: Figure S2B). Based on the above analyses, two lines (OsTCTP-OX-\#12 and OsTCTP-OX-\#14) 


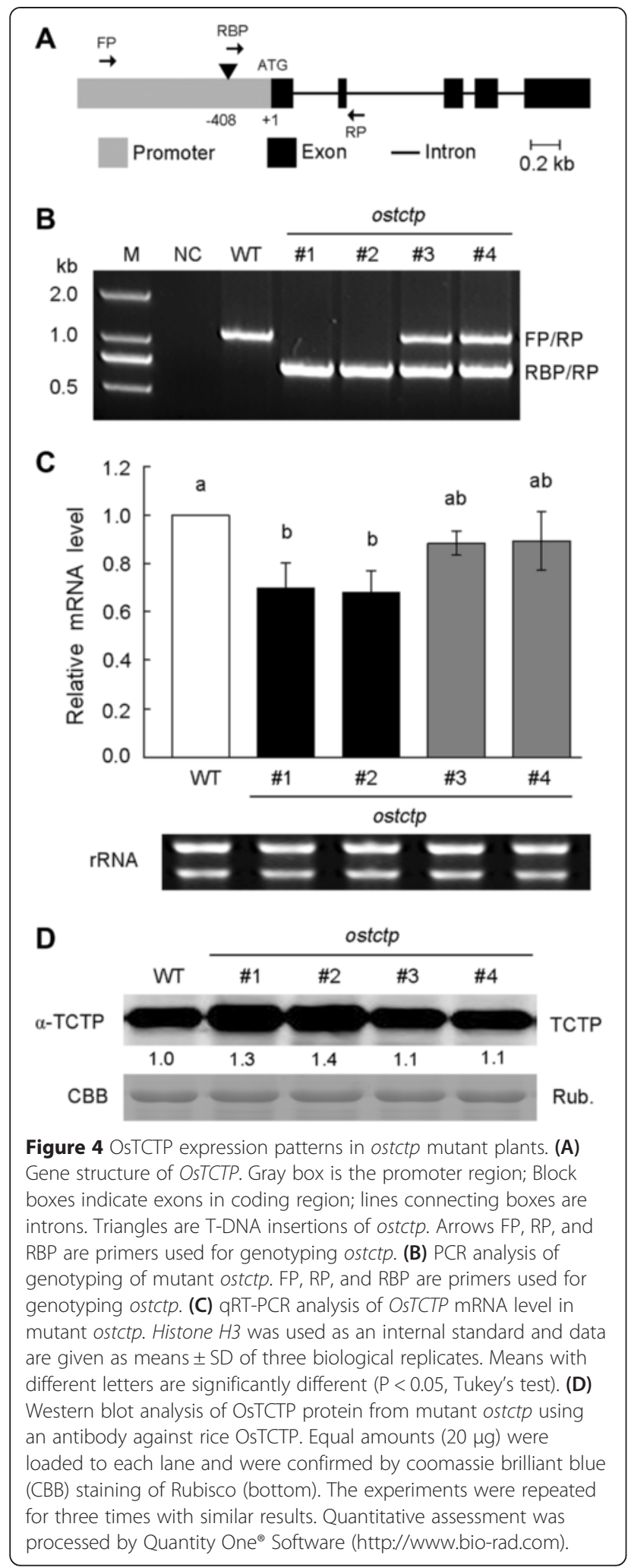

were selected for further phenotypic and functional characterization. In addition, twenty-six independent suppression lines were generated using the OsTCTP-RNAi

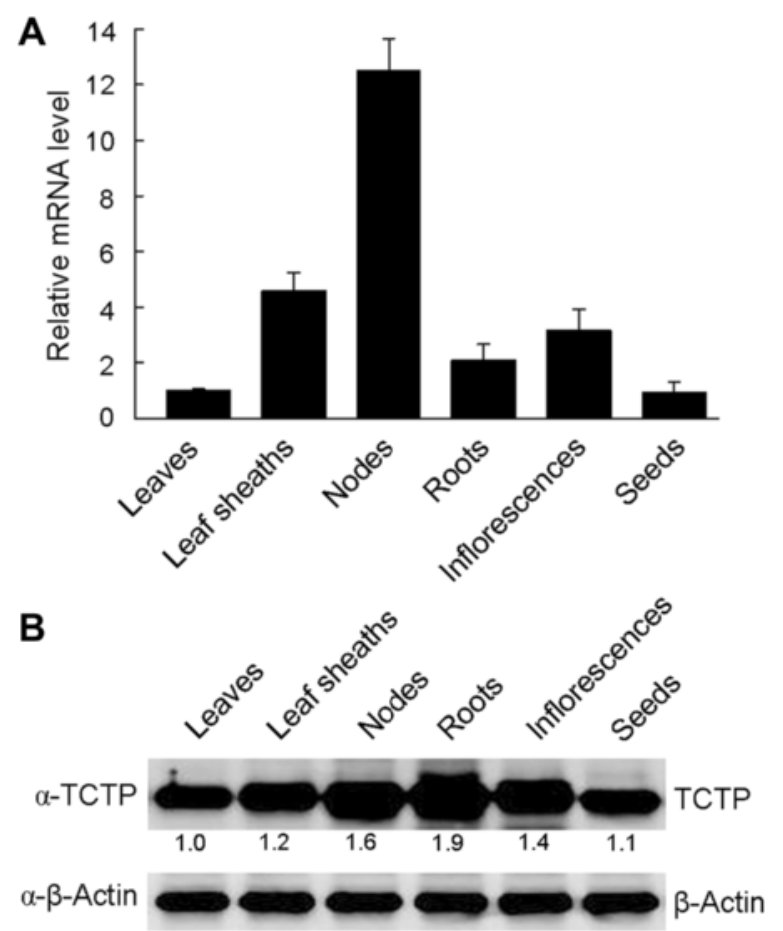

Figure $\mathbf{5}$ qRT-PCR and western blot analyses of OsTCTP in wild-type rice plants. (A) qRT-PCR analysis of OSTCTP mRNA level in wild-type rice plants. HistoneH3 was used as an internal standard and data are given as means \pm SD of three biological replicates. Means with different letters are significantly different ( $P<0.05$, Tukey's test). (B) Western blot analysis of OsTCTP protein from wild-type rice plants using an antibody against rice OsTCTP. Equal amounts $(20 \mu \mathrm{g})$ were loaded to each lane and $\beta$-actin was used as an internal standard. The experiments were repeated for three times with similar results. Quantitative assessment was processed by Quantity One ${ }^{\circledast}$ Software (http://www.bio-rad.com).

construct. Western blot analysis indicated that 20 lines showed low expression in the OsTCTP-RNAi transgenic plants (Additional file 1: Figure S5A) and 22 of them were selected to analyze by southern blot and 5 OsTCTP-RNAi lines contained a single-copy insertion (Additional file 1: Figure S5B). The production of endogenous OsTCTP protein was blocked almost completely and moderately in OsTCTP-RNAi-\#10 and OSTCTP-RNAi-\#17, respectively and they were selected for further functional analysis.

The accumulation of OsTCTP was obviously induced by $\mathrm{HgCl}_{2}$ stress (Figure 7A); therefore, OsTCTP-OX and OsTCTP-RNAi transgenic plants were evaluated for $\mathrm{Hg}$ tolerance. When WT (cv. 'Nipponbare'), VC (vector control), OsTCTP-RNAi (\#10 and \#17) and OsTCTP-OX (\#12 and \#14) were grown in the absence of $\mathrm{Hg}$, their root growth was similar (Figure 8A). However, in the presence of $0.2 \mu \mathrm{M} \mathrm{Hg}$, the root growth was inhibited more in the OsTCTP-RNAi than in the WT, VC or OsTCTP-OX transgenic plants (Figure 8A). For the OsTCTP-RNAi transgenic plants, the root elongation 


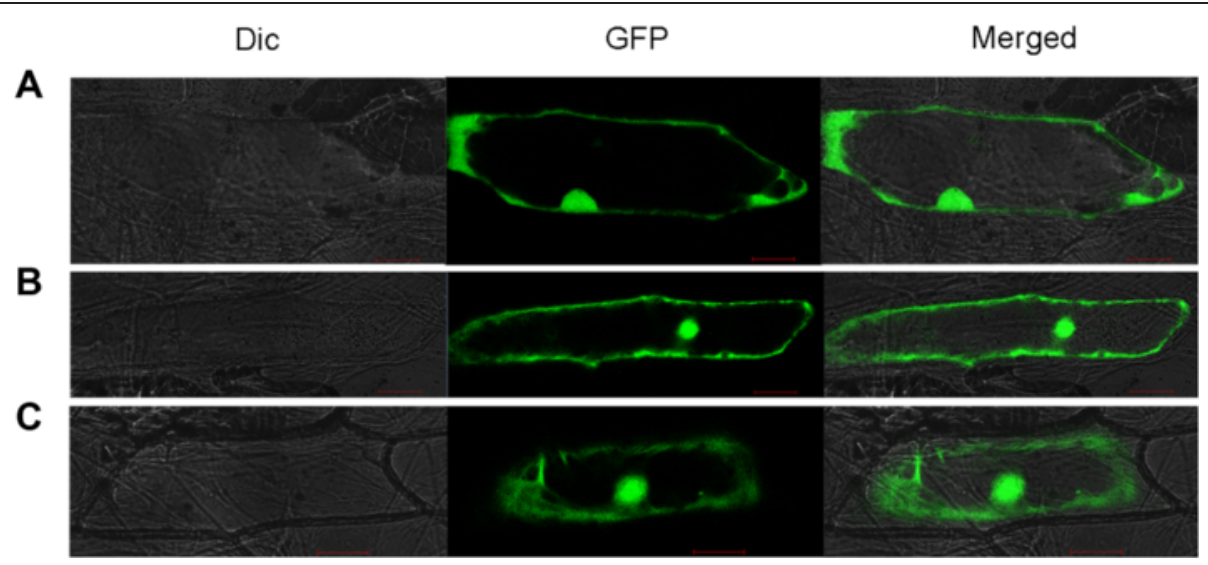

Figure 6 Subcellular localization of OsTCTP. (A) GFP protein localization in onion epidermal cells. (B) OsTCTP-GFP fusion protein localization in onion epidermal cells. (C) Plasmolysed cell transformed with OsTCTP-GFP fusion protein. Dic, bright field images; GFP, GFP fluorescence; and Merged, merged image. Scale bars $=100 \mu \mathrm{m}$.

was inhibited by approximately $61 \%$, whereas the inhibition rates were only around $52 \%$ and $37 \%$ for the control plants (WT and VC) and the OsTCTP-OX transgenic plants, respectively (Figure 8B,C). Synchronously, 6-week-old rice seedlings grown hydroponically were also subjected to $\mathrm{Hg}$ stress. The OsTCTP-RNAi transgenic plants displayed a severe leaf curl phenotype after being treated with 50 $\mu \mathrm{M} \mathrm{HgCl}_{2}$ for 3 days compared with the OsTCTP-OX transgenic plants and the control plants (WT and VC, Additional file 1: Figure S6). These results demonstrated that OsTCTP positively regulates $\mathrm{Hg}$ tolerance in rice.

$\mathrm{Hg}$ and GSH contents in the transgenic and wild-type rice plants under $\mathrm{Hg}$ treatment

To determine whether the overexpression of OsTCTP prevents $\mathrm{Hg}$ absorption or accumulation, we measured the $\mathrm{Hg}$ content in roots and shoots of the OsTCTPRNAi and OsTCTP-OX transgenic rice plants and the control plants (WT and VC). After being treated with $25 \mu \mathrm{M} \mathrm{HgCl}_{2}$ for 3 days, $\mathrm{Hg}$ residue was significantly increased in both roots and shoots of the transgenic and control rice plants. However, the concentration of $\mathrm{Hg}$ in neither roots nor shoots of the transgenic lines was different from that in the control rice plants (Figure 9), indicating that the overexpression of OsTCTP did not prevent $\mathrm{Hg}$ absorption and transport. Furthermore, the glutathione (GSH)-dependent phytochelatin (PC) synthesis pathway is one of the most important mechanisms contributing to divalent heavy metal detoxification and tolerance [38,39], so we determined the GSH content in roots of the OsTCTP-RNAi and OsTCTP-OX transgenic rice plants and the control plants (WT and VC). The level of total GSH in roots was greatly reduced with $25 \mu \mathrm{M} \mathrm{HgCl} 2$ for 12 hours, and the decreased level of GSH caused by $\mathrm{Hg}$ stress in the OsTCTP-RNAi and OsTCTP-OX transgenic rice plants showed no difference from that in the control plants (WT and VC) (Figure 10A), which is consistent with previous report [40]. At the transcriptional level, we also tested the expression of relative genes, such as two glutathione synthetase genes (Os12g 34380 and Os11g42350), two phytochelatin synthase genes (Os05g34290 and Os06g01260) and an ABCC-type transporter 1 gene (Os04g52900), but none of them had significantly altered transcripts between the transgenic rice plants (OsTCTP-RNAi and OsTCTP-OX lines) and the control plants (WT and VC) under normal and $\mathrm{Hg}$ treatment (Additional file 1: Figure S7). These results indicated that rice probably does not employ the $\mathrm{PC}$ synthesis pathway to mediate $\mathrm{Hg}$ tolerance and the OsTCTP does not affect $\mathrm{Hg}$ absorption and accumulation in rice.

\section{$\mathrm{H}_{2} \mathrm{O}_{2}$ level and changes of antioxidant enzyme activity in response to $\mathrm{Hg}$ stress}

A growing number of studies have shown that mercuric ions are able to induce oxidative stress in plants $[4,11,12,41]$. This prompted us to investigate whether ROS accumulation differentially occurred in roots of the OsTCTP-RNAi and OsTCTP-OX transgenic rice plants under $\mathrm{Hg}$ stress by quantifying the accumulation of $\mathrm{H}_{2} \mathrm{O}_{2}$. These results indicated that, under $\mathrm{Hg}$ stress condition, OsTCTP-OX transgenic lines showed significantly less accumulation of $\mathrm{H}_{2} \mathrm{O}_{2}$ compared to the control plants (WT and VC) and the OsTCTP-RNAi transgenic lines (Figure 10B), suggesting that OsTCTP may be involved in ROS homeostasis in rice plants in response to $\mathrm{Hg}$ toxicity. To further elucidate the mechanism of ROS detoxifying machinery under $\mathrm{Hg}$ stress condition, the activities of antioxidant enzymes, such as superoxide dismutase (SOD), catalase (CAT), ascorbate peroxidase (APX), and peroxidase (POD) were also analyzed. The activities of SOD, CAT, APX, and POD increased rapidly in $\mathrm{Hg}$ stress-treated OsTCTP-OX transgenic lines compared 


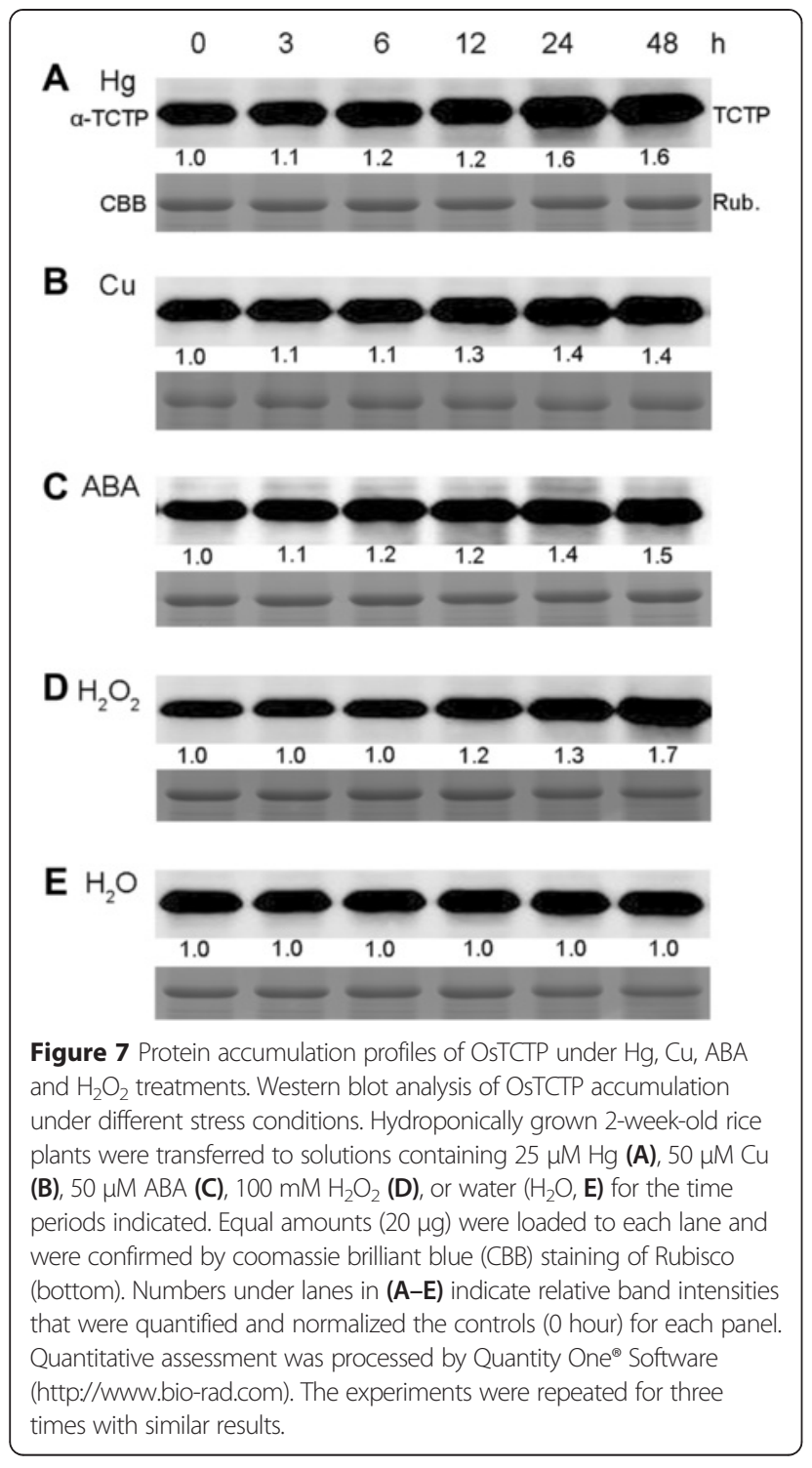

with the control plants (WT and VC) and the OsTCTPRNAi transgenic lines (Figure 10C-F), especially, in the case of CAT (Figure 10D). These results suggested that the antioxidant enzyme system is strongly promoted in the OsTCTP-OX transgenic rice plants under $\mathrm{Hg}$ treatment.

\section{Discussion}

TCTPs are conserved and play vital roles in eukaryotic organisms

Sequence comparison shows that OsTCTP, like other TCTPs, contains a series of conserved functional domains for interaction with other proteins, such as the antiapoptotic protein $\mathrm{MCL} / \mathrm{BCL}[27,42]$, the cell cycle controlling polo kinase $[27,43]$, and a $\mathrm{Na}^{+} / \mathrm{K}^{+}$ATPase $[27,44]$ (Figure 3A). A Ca ${ }^{2+}$ binding domain, a TCTP self-interaction domain and a protein transduction domain have also been identified among different TCTPs
[45-47]. Furthermore, our structural model for the OsTCTP shows high similarity to the human TCTP protein (Figure 3A,B), also suggesting that TCTPs from different species are strictly conserved in both amino acids and protein structure. TCTPs are ubiquitously expressed in all eukaryotic organisms and are related to various stress responses. It has been established that TCTP levels are highly regulated in response to a wide range of extracellular and intracellular signals, and various stress conditions such as starvation, heat shock, heavy metals, calcium stress or pro-apoptotic signals [24]. In Drosophila, disruption of $d T C T P$ expression in an organ-specific manner leads to size reduction of the targeted organ due to a reduction in cell numbers and defects in cell growth [48]. Interestingly, plant TCTP can fully rescue cell proliferation defects in Drosophila loss of function for dTCTP [25], indicating that TCTPs are functionally conserved between plant and animal species.

\section{OsTCTP is required for $\mathrm{Hg}$ tolerance in rice}

OsTCTP is ubiquitously expressed in all tested plant tissues (Figure 5), whose expression is rapidly induced by $\mathrm{Hg}$ at both mRNA level (Additional file 1: Figure S8) and protein level (Figure 7A). Overexpression of OsTCTP resulted in increased tolerance to $\mathrm{Hg}$, while knockdown of OsTCTP by RNA interference led to sensitivity to $\mathrm{Hg}$ (Figure 8). These results indicate that OSTCTP is required for $\mathrm{Hg}$ tolerance in rice. Knockdown of OsTCTP led to a huge increase in Hg-induced $\mathrm{H}_{2} \mathrm{O}_{2}$ in RNA interference lines under $\mathrm{Hg}$ stress condition, whereas overexpression of OsTCTP had opposite effect (Figure 10B). Overexpression of OsTCTP promoted the activities of SOD, CAT, APX, and POD (Figure $10 \mathrm{C}-\mathrm{F}$ ), and decreased the $\mathrm{Hg}$-induced $\mathrm{H}_{2} \mathrm{O}_{2}$ in overexpression lines under $\mathrm{Hg}$ stress condition. These results suggested that OsTCTP functions to enhance tolerance to $\mathrm{Hg}$ stress through the regulation of ROS and their scavengers, although these regulating mechanisms for activities of antioxidant enzymes remain to be molecularly characterized.

\section{OsTCTP is not an $\mathrm{N}$-glycoprotein}

It has been shown that the protein accumulation and potential glycosylation of TCTP is regulated by glucose in pancreatic beta cells [49]. Therefore, we predicted the potential glycosylation sites in OsTCTP sequence on NetNGlyc website (http://www.cbs.dtu. $\mathrm{dk} /$ services/NetNGlyc/) and N48 (Asn 48) and N97 (Asn 97) were forecasted to be the potential $\mathrm{N}$ glycosylation sites (Additional file 1: Figure S9A). Previous reports have demonstrated that the mobility shift will change and result in a small band when the polysaccharide chain is released from the glycoprotein [50,51]. To confirm the N-glycosylation sites of OsTCTP, 


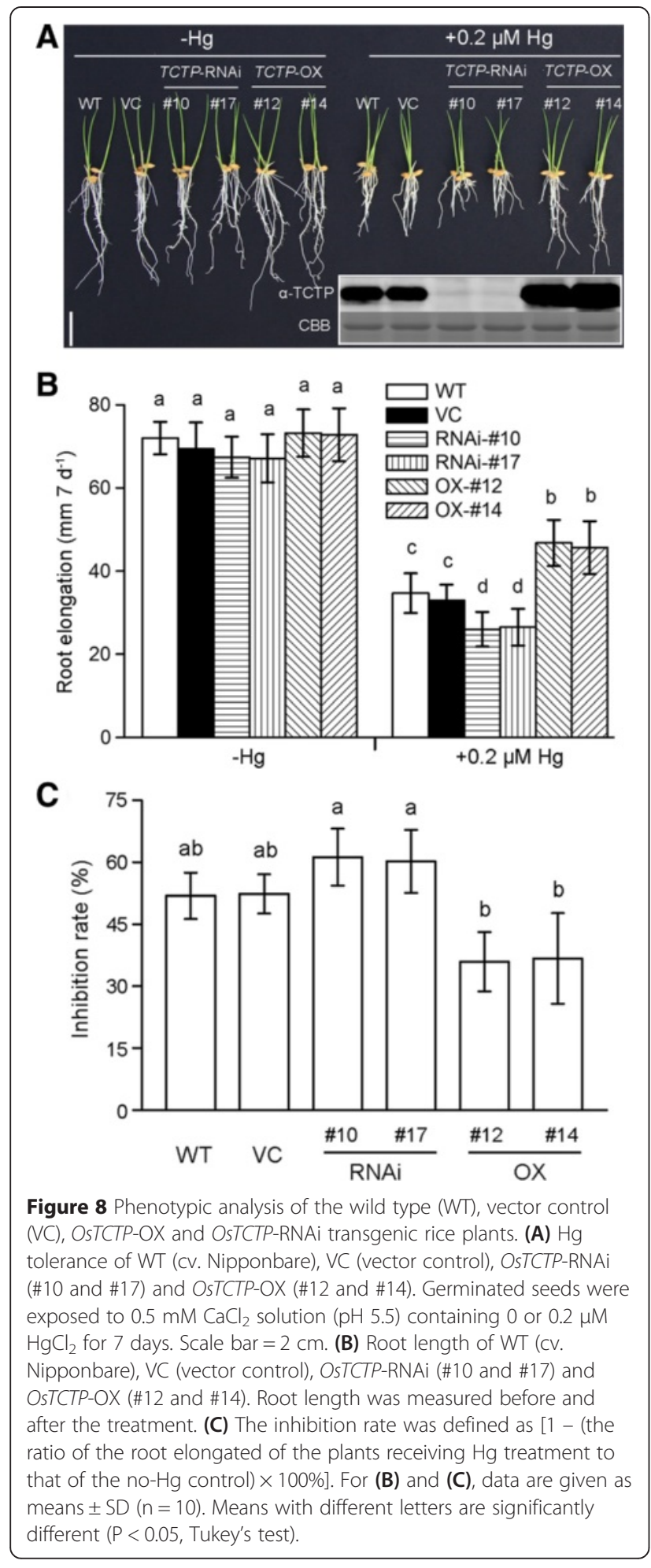

we performed site-directed mutagenesis of the two potential N-glycosylation sites by substituting Asn with Gln (N48Q and N97Q; Additional file 1: Figure S9B). The mutated genes were inserted into the HA-tagged expression vectors and transiently expressed in Nicotiana

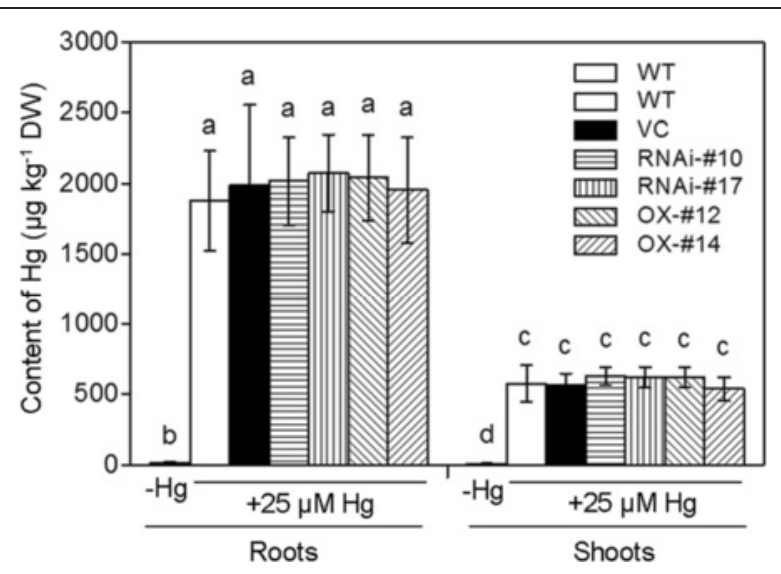

Figure 9 Mercury concentrations in roots or leaves of the wild type (WT), vector control (VC), OsTCTP-OX and OsTCTP-RNAi transgenic rice seedlings under $25 \mu \mathrm{M} \mathrm{HgCl}_{2}$ treatment for 3 days. Data are given as the mean \pm SD of three biological replicates. Means with different letters are significantly different ( $P<0.05$, Tukey's test).

benthamiana leaves as described by Sparkes et al. [52]. Western blot analysis showed that there was no difference in mobility shift of wild-type OsTCTP and its mutants (Additional file 1: Figure S9C). Altogether, these results suggested that $\mathrm{N} 48$ and $\mathrm{N} 97$ are not the potential N-glycosylation sites and OsTCTP is not an Nglycoprotein.

\section{Conclusions}

In this study, we molecularly and functionally characterized a rice gene (Os11g43900, OsTCTP) and our data establish that OsTCTP plays a critical role in $\mathrm{Hg}$ tolerance by regulating ROS production and scavenging and overexpression of OsTCTP increases $\mathrm{Hg}$ resistance, whereas knockdown of OsTCTP has an opposite effect. In addition, further research is needed to understand how the OsTCTP regulates the activities of antioxidant enzymes in Hg stress signaling.

\section{Methods}

\section{Plant materials and growth conditions}

A wild-type rice (Oryza sativa L.) cultivar 'Nipponbare' belonging to sp. japonica was used in this study. The wildtype and transgenic plants were grown either in a greenhouse [average temperature of $28 / 24^{\circ} \mathrm{C}$ (day/night), relative humidity $60-80 \%$, photosynthetically active radiation 200 $400 \mu \mathrm{mol} \cdot \mathrm{m}^{-2} \mathrm{~s}^{-1}$ and photoperiod of $14 \mathrm{~h}$ day $/ 10 \mathrm{~h}$ night] or in an experimental field at the Institute of Plant Sciences, Zhejiang University (Hangzhou, China).

\section{Plasmid construction and plant transformation}

All constructs were made using standard procedures [53]. A universal expression vector pCUN1301 which carries a maize (Zea mays) ubiquitin 1 (Ubil) promoter 


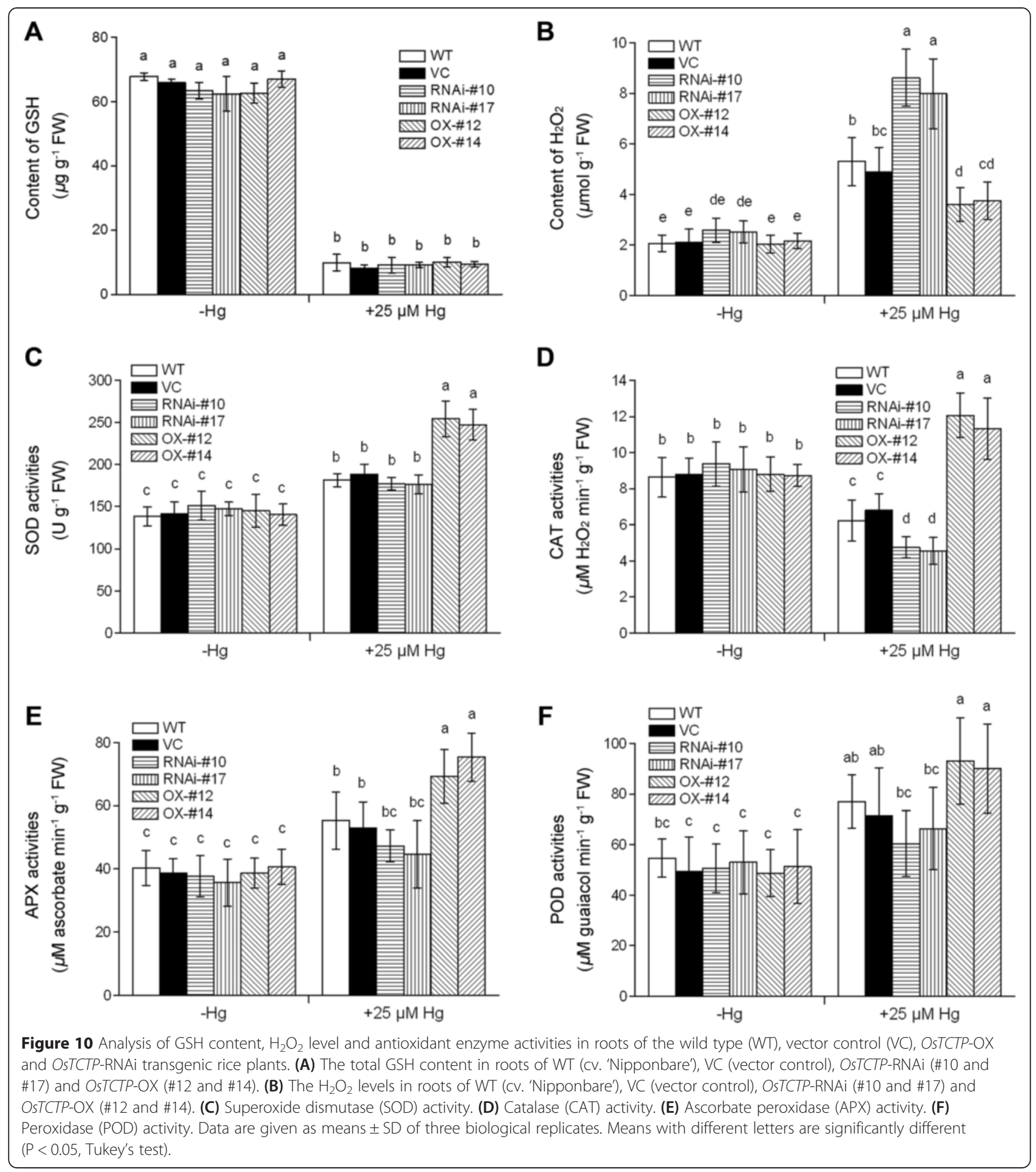

and a Nos terminator cassette was constructed as previously described by Chen et al. [54]. To make the overexpression constructs, two putative CDSs of OsTCTP were amplified by PCR using primer pairs (Additional file 2: Table S1) and subcloned into the plasmid pCUN1301 to result in the overexpression constructs (OsTCTPa-OX and $O s T C T P b-O X)$. The OsTCTPa-OX and OsTCTPb-
OX constructs were confirmed by sequencing. To make a dsRNAi construct, DNA fragments (508 bp, including 119 bp intact 5'UTR and 389 bp coding sequence) with different restriction enzyme sites at both ends was amplified by PCR using RNAi1 and RNAi2 primer pairs (Additional file 2: Table S1). The two PCR fragments were inserted at inverted repeats into the 
pKANNIBAL vector to generate a hairpin RNAi construct [55], which was then subcloned into plasmid pCUN1301 to result in the RNAi construct (OsTCTPRNAi).

The Agrobacterium-mediated transformation was performed using vigorously growing calli derived from mature embryos of rice (cv. 'Nipponbare') following a standard procedure [32].

\section{PCR selection, southern blot analysis and GUS staining}

The transgenic plants were regenerated from transformed calli by selecting for hygromycin resistance. The regenerated plants were confirmed by PCR analysis using the hygromycin phosphotransferase-specific primer (Additional file 2: Table S1). Plant genomic DNAs were prepared from leaves of rice leaves using cetyltrimethylammonium bromide [56] and were quantified using SMA4000 UV-vis Spectrophotometer (Merinton). Thirty micrograms of DNA were digested with EcoRI; electrophoresed on $0.8 \%$ agarose gel; blotted on a nylon membrane (Roche) with a high-salt buffer [57]. A hygromycin phosphotransferase probe was generated using the DIG-High Prime DNA Labeling and Detection Starter Kit I or II (Roche), and the hybridization signals were detected according to the standard manufacturer's instructions. GUS staining was conducted essentially as previously described by Jefferson $e t$ al. [58].

\section{Protein purification and antibody production}

A gene fragment between +1 and +360 (related to the ATG at $+1 \mathrm{bp}$ ) was amplified from the OsTCTP coding sequence by PCR and then inserted into the NdeI and $X h o I$ restriction sites of the pET-28a (+) to generate the expression vector (OsTCTP-28a). The plasmid encoding the His-fusion protein was transformed into Escherichia coli BL21 (DE3) strain (Novagen). When the culture of the transformed cells reached an $\mathrm{A}_{600}$ of $0.8-1.0$, protein accumulation was induced by $1 \mathrm{mM}$ isopropyl 1-thio- $\beta$ D-galactopyranoside (IPTG) at $20^{\circ} \mathrm{C}$ for $4-6 \mathrm{~h}$. The Histaged protein was purified by using His•Bind purification kit (Novagen) according to the manufacturer's protocol. The quality of the purified protein was assessed by SDSPAGE and coomassie brilliant blue (CBB) staining. The buffer with the highly purified OsTCTP protein was exchanged to $1 \times$ PBS using a dialyzer. This antigen solution (5 $\mathrm{mg} \mathrm{mL}^{-1}$ protein) was injected into rabbits using standard protocols for antibody production [53], and the resulting antiserum was used for western blot.

\section{Protein extraction and western blot analysis}

Samples (approximately $0.1 \mathrm{~g}$ ) were ground to powder with liquid nitrogen and homogenized in $400 \mu \mathrm{L}$ extraction buffer [50 mM Tris- $\mathrm{HCl}$ ( $\mathrm{PH} 7.5), 150 \mathrm{mM} \mathrm{NaCl}$, $5 \mathrm{mM}$ EDTA, 0.5\% Sodium deoxycholate, 0.5\% Triton
X-100, 0.1\% SDS, 0.2\% Nonidet P-40, 1 mM PMSF, $5 \mathrm{mM}$ DTT and 10\% Glycerol]. The homogenates were shaken repeatedly on ice for $30 \mathrm{~min}$ and centrifuged at $16,000 \times g$ for $20 \mathrm{~min}$ at $4{ }^{\circ} \mathrm{C}$, and the resulting supernatants were used for western blot analysis. Twenty micrograms of supernatants were mixed with $5 \mu \mathrm{L}$ of $4 \times$ SDS sample buffer [250 mM Tris- $\mathrm{HCl}(\mathrm{pH}$ 6.8), 8\% SDS, $40 \%$ glycerol, $0.4 \%$ Bromophenol blue and $6 \% \beta$ mercaptoethanol], and then incubated at $85^{\circ} \mathrm{C}$ for $10 \mathrm{~min}$. The samples were then analyzed by $4 \%-12 \%(\mathrm{w} / \mathrm{v})$ SDS-PAGE. After electrophoresis, proteins were electroblotted to nitrocellulose membranes. Membranes were blocked in 5\% nonfat dried milk in TBS-T [20 mM Tris$\mathrm{HCl}(\mathrm{pH} 7.4), 150 \mathrm{mM} \mathrm{NaCl}$ and $0.05 \%$ Tween 20] overnight at $4{ }^{\circ} \mathrm{C}$ and then washed for $3 \times 10 \mathrm{~min}$ in TBS-T. The membranes were incubated with the rabbit OsTCTP polyclonal antibody $(1: 2500)$ or with the $\beta$-actin mouse monoclonal antibody (1:1000) diluted with $1 \%$ BSA in TBS-T for $1.5 \mathrm{~h}$ at room temperature. Next, the membranes were washed in TBS-T for $3 \times 10 \mathrm{~min}$, and incubated for $1 \mathrm{~h}$ with goat anti-rabbit IgG or goat anti-mouse IgG (1:5000 dilution in TBS-T with $1 \%$ BSA) conjugated to horseradish peroxidase, followed by a washing for $3 \times$ $10 \mathrm{~min}$ in TBS-T. Finally, chemiluminescent signals were detected using Luminata Forte Western HRP substrate (Millipore). The quantitative assessment was processed by Quantity One ${ }^{\circ}$ Software (http://www.bio-rad.com).

\section{RNA extraction and qRT-PCR analysis}

Total RNA was extracted from materials using RNAprep Pure Plant Kit (Tiangen), and cDNA was reverse transcribed from $1 \mu \mathrm{g}$ of total RNA using M-MLV reverse transcriptase (Takara). Relative quantification of gene expression by qRT-PCR was performed on a LightCycler ${ }^{\circ}$ 480 II instrument (Roche). qRT-PCR was performed in an optical 384-well plate, including $10 \mu \mathrm{L} 2 \times$ SYBR Green Master mix reagent (Takara), $1 \mu \mathrm{L}$ 1:10-diluted template cDNA, and $0.2 \mu \mathrm{M}$ of each gene-specific primers, in final volume of $20 \mu \mathrm{L}$, using the thermal cycles as follows: $95^{\circ} \mathrm{C}$ for $1 \mathrm{~min} ; 40$ or 45 cycles of $95^{\circ} \mathrm{C}$ for $10 \mathrm{~s}$; $55^{\circ} \mathrm{C}$ for $15 \mathrm{~s}$; and $72^{\circ} \mathrm{C}$ for $20 \mathrm{~s}$. Disassociation curve analysis was performed as follows: $95^{\circ} \mathrm{C}$ for $15 \mathrm{~s}$; $60^{\circ} \mathrm{C}$ for $15 \mathrm{~s} ; 94^{\circ} \mathrm{C}$ for $1 \mathrm{~min}$. The relative expression levels were calculated by the $\Delta C_{T}$ method [59]. Rice histoneH3 gene was used as endogenous control which was stable throughout the $\mathrm{Al}$ treatment [60]. The primers used for studying gene expression are listed in Additional file 2: Table S1. The reactions were performed in triplicate, and the results were averaged.

\section{Isolation and analysis of T-DNA insertion lines}

The rice T-DNA insertion mutant ostctp was identified from the Rice T-DNA Insertion Sequence Database (http://cbi.khu.ac.kr) [36], Kyung Hee University, Korea. 
The homozygote and heterzygote screening was performed using PCR as described previously [37]. qRTPCR and western blot were performed to determine knockdown or knockout of the OSTCTP transcripts and translation products, respectively.

\section{Transient expression of the fused sGFP protein}

To make a GFP construct, the OsTCTP coding region was fused to sGFP and subcloned into the pCAMBIA1300 vector with a $35 \mathrm{~S}$ promoter to generate the GFP construct (OsTCTP-GFP). The DNA constructs were introduced into onion (Allium cepa) epidermal cells as described previously [61].

\section{Chemical and abiotic treatments}

Chemical treatments and mechanical wounding were conducted essentially as previously described by Xiong \& Yang [62]. For chemical treatments, roots of 2-weekold seedlings were immersed in solutions containing abscisic acid (ABA, $0.1 \mathrm{mM}$ ), jasmonic acid (JA, $0.1 \mathrm{mM})$, salicylic acid (SA, $1 \mathrm{mM})$, 1-naphthylacetic acid (NAA, $0.1 \mathrm{mM}$ ), or hydrogen peroxide $\left(\mathrm{H}_{2} \mathrm{O}_{2}\right.$, $100 \mathrm{mM}$ ) for 0 to 48 hours under the greenhouse conditions. Mechanical wounding was achieved by crushing rice leaves with a hemostat. Abiotic treatments were conducted mainly according to Saijo et al. [63] and Jang et al. [64]. For the salt stress treatment, roots of 2-weekold seedlings were immersed in $200 \mathrm{mM} \mathrm{NaCl}$ solution for 0 to 48 hours under the greenhouse conditions. For heavy metal stress, roots of 2-week-old seedlings were immersed in solutions containing $\mathrm{HgCl}_{2}(25 \mu \mathrm{M})$ or $\mathrm{CuSO}_{4}(50 \mu \mathrm{M})$ for 0 to 48 hours under the greenhouse conditions, respectively. Drought stress was induced by 15\% polyethylene glycol (PEG) $6000\left(150 \mathrm{~g} \mathrm{~L}^{-1}\right)$ solution for 0 to 48 hours under the greenhouse conditions.

\section{Evaluation of the $\mathrm{Hg}$ tolerance and determination of $\mathrm{Hg}$ content}

For evaluation of the $\mathrm{Hg}$ tolerance, seeds of WT (cv. 'Nipponbare') and T2 transgenic seeds of $\mathrm{VC}$ (vector control), OsTCTP-RNAi (\#10 and \#17) and OsTCTP-OX (\#12 and \#14) were germinated in water and solution containing $25 \mathrm{mg} \mathrm{L}^{-1}$ hygromycin $\mathrm{B}$ (Roche), respectively, at $28^{\circ} \mathrm{C}$ for 3 days, and then transferred to a plastic net floating on $0.5 \mathrm{mM} \mathrm{CaCl}_{2}$ solution ( $\mathrm{pH}$ 5.5) containing 0 or $0.2 \mu \mathrm{M} \mathrm{HgCl}_{2}$. After 7 days, the root length was measured using a ruler. The inhibition rate was defined as $[1$ - (the ratio of the root elongated of the plants receiving $\mathrm{Hg}$ treatment to that of the no- $\mathrm{Hg}$ control) $\times$ 100\%]. 2-week-old rice seedlings of WT (cv. 'Nipponbare'), VC (vector control), OsTCTP-RNAi (\#10 and \#17) and OsTCTP-OX (\#12 and \#14) treated with or without $25 \mu \mathrm{M} \mathrm{HgCl}_{2}$ for 3 days were used for the determination of the $\mathrm{Hg}$ concentration. The sample preparation and
$\mathrm{Hg}$ determination was performed as described previously $[65,66]$. Briefly, the dried sample $(0.1 \mathrm{~g})$ was submerged in $5 \mathrm{~mL}$ of the acidic oxidative mixture $\left(\mathrm{HNO}_{3}\right.$ :$\left.\mathrm{H}_{2} \mathrm{O}_{2}: \mathrm{H}_{2} \mathrm{O} ; 0.6: 0.4: 1 ; \mathrm{v} / \mathrm{v}\right)$, and autoclave digested $\left(120^{\circ} \mathrm{C}, 1.5\right.$ atmospheres, $\left.30 \mathrm{~min}\right)$. Once cooled to room temperature, the digests were filtered through a polyvinylidenefluoride (PVDF) filter and diluted in water to $50 \mathrm{~mL}$. Hg was analysed using a flux injection absorption spectrometer, equipped with the cold-vapour generator FIAS (Perkin Elmer, USA).

\section{Measurement of the $\mathrm{GSH}, \mathrm{H}_{2} \mathrm{O}_{2}$ and antioxidant enzyme assays}

For VC (vector control), OsTCTP-RNAi (\#10 and \#17) and OsTCTP-OX (\#12 and \#14) transgenic plants, seeds of T2 generation selected with $25 \mathrm{mg} \mathrm{L}^{-1}$ hygromycin B (Roche) were employed for the experiments. 2-week-old rice seedlings of WT (cv. 'Nipponbare'), VC (vector control), OsTCTP-RNAi (\#10 and \#17) and OsTCTP-OX (\#12 and \#14) treated with or without $25 \mu \mathrm{M} \mathrm{HgCl}_{2}$ for 12 hours were used for measurement of the GSH and $\mathrm{H}_{2} \mathrm{O}_{2}$ contents as described previously [67-69]. For the determination of GSH, roots of rice plants $(0.1 \mathrm{~g}$ fresh weight) were ground with liquid nitrogen and homogenized in $1 \mathrm{~mL}$ cold $5 \%$ trichloroacetic acid. After centrifugation at $4^{\circ} \mathrm{C}$ and $10,000 \times g$ for $10 \mathrm{~min}$, the supernatant was used to measure the content of GSH according to the instruction of the total GSH assay kit (Beyotime, China). For $\mathrm{H}_{2} \mathrm{O}_{2}$ measurement, roots of rice plants $(0.2 \mathrm{~g}$ fresh weight) were homogenized in $1 \mathrm{~mL}$ cold acetone in a mortar with silica sand. The extract and washings were centrifuged at $3,000 \times g$ for $15 \mathrm{~min}$ and the coloring materials were adsorbed by activated carbon. Then $200 \mu \mathrm{L}$ supernatant were added to $1 \mathrm{~mL}$ of reaction buffer $\left[0.25 \mathrm{mM} \mathrm{FeSO} 4,0.25 \mathrm{mM}(\mathrm{NH} 4)_{2} \mathrm{SO}_{4}, 25 \mathrm{mM}\right.$ $\mathrm{H}_{2} \mathrm{SO}_{4}, 1.25 \mathrm{mM}$ xylenol orange, and $1 \mathrm{mM}$ sorbitol] at room temperature for $1 \mathrm{~h}$. The level of $\mathrm{H}_{2} \mathrm{O}_{2}$ was estimated spectrophotometrically at $560 \mathrm{~nm}$ using a spectrophotometer. The results were calculated on the basis of a standard curve using standard hydrogen peroxide solutions.

For antioxidant enzyme assays, 2-week-old rice seedlings of WT (cv. 'Nipponbare'), VC (vector control), OsTCTP-RNAi (\#10 and \#17) and OsTCTP-OX (\#12 and \#14) treated with or without $25 \mu \mathrm{M} \mathrm{HgCl}_{2}$ for $12 \mathrm{~h}$ were used for antioxidant enzyme assays. Roots of rice plants ( $0.2 \mathrm{~g}$ fresh weight) were homogenized and extracted in $1 \mathrm{~mL}$ of ice cold $50 \mathrm{mM}$ sodium phosphate buffer (pH 7.8) containing $1 \mathrm{mM}$ EDTA at $4^{\circ} \mathrm{C}$. After centrifugation at $13,000 \mathrm{rpm}$ for $10 \mathrm{~min}$, the supernatant was used as a crude enzyme extract. The activity of superoxide dismutase (SOD), catalase (CAT), peroxidase (POD) 
and ascorbate peroxidase (APX) was determined as described previously [70].

\section{Site-directed mutagenesis and $\mathrm{N}$-glycosylation analysis}

To make mutant OsTCTP proteins, N48Q and N97Q changes were made by site-directed mutagenesis, using an in vitro synthesis method (Transgen). Each wild-type and mutated OsTCTP was subcloned into the transient expression vector pCHA at KpnI and BamHI sites, and the constructs were transformed into Nicotiana benthamiana via Agrobacterium EHA105-mediated transformation [48]. Protein extraction and western blot analysis were performed following a standard procedure as described above.

\section{Phylogenetic analysis and homology modelling}

We constructed neighbor-joining (NJ) trees using the MEGA software (version 5.2) (http://www.megasoftware. net) [71] with the following parameters: Poisson correction, pairwise deletion, and bootstrap (1000 replicates; random seed). This was performed essentially as described by Zhang et al. [72].

The structure of the OsTCTP protein (Os11g43900) was modeled using the known structure of the human TCTP (PDB ID 2HR9, http://www.rcsb.org) as a template on the Swiss-Model workspace (http://swissmodel.expasy.org) [73].

\section{Statistical analysis}

Data shown are mean \pm standard deviation (SD) for at least three independent experiments. Mean differences were compared using the statistical software data processing system (DPS v7.05) [74], followed by the Tukey's test and the difference at $\mathrm{P}<0.05$ and 0.01 is considered as significant and highly significant, respectively.

\section{Availability of supporting data}

The data set supporting the results of this article is available in the National Center for Biotechnology Information repository, [GenBank: KR080533; http://www.ncbi.nlm.nih. gov/genbank/].

\section{Additional files}

Additional file 1: Figures S1-S9. Figure S1. Comparison of OSTCTPa and OSTCTPb. Figure S2. Western blot and southern blot analyses of OSTCTPa transgenic rice plants. Figure S3. Southern blot analysis of OsTCTPb transgenic rice plants. Figure S4. Protein accumulation profiles of OsTCTP under $\mathrm{NaCl}, \mathrm{MW}, \mathrm{PEG}, \mathrm{SA}$, JA or NAA treatments. Figure $\mathbf{S 5 .}$ Western blot and southern blot analyses of OsTCTP-RNAi transgenic rice plants. Figure S6. Phenotypic analysis of the wild type (WT), vector control (VC), OsTCTP-OX and OsTCTP-RNAi transgenic rice plants. Hg tolerance of WT (cv. Nipponbare), VC (vector control), OsTCTP-RNAi (\#10 and \#17) and OsTCTP-OX (\#12 and \#14). Figure S7. Expression patterns of some Hg stress-related genes in the wild type (WT), vector control (VC), OSTCTP-OX and OSTCTP-RNAi transgenic rice plants treated without or with $25 \mu \mathrm{M} \mathrm{HgCl} 2$ for 12 hours. Figure S8. qRT-PCR analysis of OsTCTP
mRNA level in roots and shoots of the wild-type (WT) plants treated without or with $25 \mathrm{\mu M} \mathrm{HgCl}$ for 0 to 24 hours. Figure S9. Analysis of potential N-glycosylation sites in OsTCTP sequence.

Additional file 2: Table S1. Oligonucleotide primers used in this study.

\section{Abbreviations}

Hg: Mercury; TCTP: Translationally controlled tumor protein; ROS: Reactive oxygen species; TOR: Target of rapamycin; GFP: Green fluorescent protein; OX: Overexpression; RNAi: RNA interference; WT: Wild type; VC: Vector control; PEG: Polyethylene glycol; ABA: Abscisic acid; NAA: 1-

Naphthaleneacetic acid; SA: Salicylic acid; JA: Jasmonic acid; GSH: Glutathione; PC: Phytochelatin; SOD: Superoxide dismutase; CAT: Catalase; APX: Ascorbate peroxidase; POD: Peroxidase; IPTG: 1-thio- $\beta$-Dgalactopyranoside; CBB: Coomassie brilliant blue; SD: Standard deviation.

\section{Competing interests}

The authors declare that they have no competing interests.

\section{Authors' contributions}

ZQW and SJZ conceived and designed the research. ZQW, GZL, QQG and GXL conducted the experiments and analyzed the data. ZQW and SJZ wrote the manuscript. All authors read and approved the manuscript.

\section{Acknowledgements}

This work was supported by the National Natural Science Foundation of China (Grant No. 31210103907), the Changjiang Scholarship and Innovative Research Team (Grant No. IRT1185) and the Fundamental Research Funds for the Central Universities.

\section{Author details}

${ }^{1}$ State Key Laboratory of Plant Physiology and Biochemistry, College of Life Sciences, Zhejiang University, Hangzhou 310058, China. ${ }^{2}$ College of

Agronomy and Biotechnology, Zhejiang University, Hangzhou 310058, China.

Received: 22 October 2014 Accepted: 21 April 2015

Published online: 20 May 2015

\section{References}

1. Carrasco-Gil S, Siebner H, Leduc DL, Webb SM, Millán R, Andrews JC, et al. Mercury localization and speciation in plants grown hydroponically or in a natural environment. Environ Sci Technol. 2013;47(7):3082-90.

2. Tchounwou PB, Ayensu WK, Ninashvili N, Sutton D. Environmental exposure to mercury and its toxicopathologic implications for public health. Environ Toxicol. 2003;18(3):149-75.

3. Chen J, Yang ZM. Mercury toxicity, molecular response and tolerance in higher plants. Biometals. 2012;25(5):847-57.

4. Israr M, Sahi S, Datta R, Sarkar D. Bioaccumulation and physiological effects of mercury in Sesbania drummondii. Chemosphere. 2006;65(4):591-8.

5. Ruiz ON, Alvarez D, Torres C, Roman L, Daniell H. Metallothionein expression in chloroplasts enhances mercury accumulation and phytoremediation capability. Plant Biotechnol J. 2011;9(5):609-17.

6. Zhou ZS, Yang SN, Li H, Zhu CC, Liu ZP, Yang ZM. Molecular dissection of mercury-responsive transcriptome and sense/antisense genes in Medicago truncatula. J Hazard Mater. 2013;252-253:123-31.

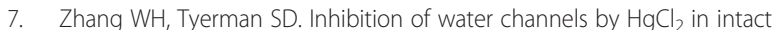
wheat root cells. Plant Physiol. 1999;120(3):849-58.

8. Patra M, Sharma A. Mercury toxicity in plants. Bot Rev. 2000;66(3):379-422.

9. Chen J, Shiyab S, Han FX, Monts DL, Waggoner CA, Yang Z, et al. Bioaccumulation and physiological effects of mercury in Pteris vittata and Nephrolepis exaltata. Ecotoxicology. 2009;18(1):110-21.

10. Pisani T, Munzi S, Paoli L, Bačkor M, Kováčik J, Piovár J, et al. Physiological effects of mercury in the lichens Cladonia arbuscula subsp. mitis (Sandst.) Ruoss and Peltigera rufescens (Weiss) Humb. Chemosphere. 2011:82(7):1030-7.

11. Cho UH, Park JO. Mercury induced oxidative stress in tomato seedlings. Plant Sci. 2000;156(1):1-9.

12. Cargnelutti D, Tabaldi LA, Spanevello RM, de Oliveira JG, Battisti V, Redin M, et al. Mercury toxicity induces oxidative stress in growing cucumber seedlings. Chemosphere. 2006;65(6):999-1006. 
13. Niu Z, Zhang $X$, Wang $S$, Zeng $M$, Wang Z, Zhang $Y$, et al. Field controlled experiments on the physiological responses of maize (Zea mays L.) leaves to low-level air and soil mercury exposures. Environ Sci Pollut Res Int. 2014;21(2):1541-7.

14. Han Y, Xuan W, Yu T, Fang WB, Lou TL, Gao Y, et al. Exogenous hematin alleviates mercury-induced oxidative damage in the roots of Medicago sativa. J Integr Plant Biol. 2007;49(12):1703-13.

15. Zhang $H$, Feng $X$, Larssen T, Shang L, Li P. Bioaccumulation of methylmercury versus inorganic mercury in rice (Oryza sativa L.) grain. Environ Sci Technol. 2010:44(12):4499-504.

16. Meng B, Feng X, Qiu G, Wang D, Liang P, Li P, et al. Inorganic mercury accumulation in rice (Oryza sativa L.). Environ Toxicol Chem. 2012;31(9):2093-8.

17. Feng X, Li P, Qiu G, Wang S, Li G, Shang L, et al. Human exposure to methylmercury through rice intake in mercury mining areas, Guizhou Province. China Environ Sci Technol. 2008;42(1):326-32.

18. Zhang H, Feng $X$, Larssen $T$, Qiu G, Vogt RD. In inland China, rice, rather than fish, is the major pathway for methylmercury exposure. Environ Health Perspect. 2010;118(9):1183-8.

19. Thomas $\mathrm{G}$, Luther $\mathrm{H}$. Transcriptional and translational control of cytoplasmic proteins after serum stimulation of quiescent Swiss 3 T3 cells. Proc Natl Acad Sci U S A. 1981;78(9):5712-6.

20. Yenofsky R, Bergmann I, Brawerman G. Messenger RNA species partially in a repressed state in mouse sarcoma ascites cells. Proc Natl Acad Sci U S A. 1982;79(19):5876-80.

21. Böhm H, Benndorf R, Gaestel M, Gross B, Nürnberg P, Kraft R, et al. The growth-related protein P23 of the Ehrlich ascites tumor: Translational control, cloning and primary structure. Biochem Int. 1989;19(2):277-86.

22. MacDonald SM, Rafnar T, Langdon J, Lichtenstein LM. Molecular identification of an IgE-dependent histamine-releasing factor. Science. 1995;269(5224):688-90.

23. Li F, Zhang D, Fujise K. Characterization of fortilin, a novel antiapoptotic protein. J Biol Chem. 2001;276(50):47542-9.

24. Bommer UA, Thiele BJ. The translationally controlled tumour protein (TCTP). Int J Biochem Cell Biol. 2004;36(3):379-85.

25. Brioudes F, Thierry AM, Chambrier P, Mollereau B, Bendahmane M Translationally controlled tumor protein is a conserved mitotic growth integrator in animals and plants. Proc Natl Acad Sci U S A. 2010;107(37):16384-9.

26. Amson R, Pece S, Marine JC, Di Fiore PP, Telerman A. TPT1/ TCTP-regulated pathways in phenotypic reprogramming. Trends Cell Biol. 2013;23(1):37-46.

27. Berkowitz O, Jost R, Pollmann S, Masle J. Characterization of TCTP, the translationally controlled tumor protein, from Arabidopsis thaliana. Plant Cell. 2008;20(12):3430-47.

28. Kim YM, Han YJ, Hwang OJ, Lee SS, Shin AY, Kim SY, et al. Overexpression of Arabidopsis translationally controlled tumor protein gene AtTCTP enhances drought tolerance with rapid ABA-induced stomatal closure. Mol Cells. 2012:33(6):617-26.

29. Hinojosa-Moya JJ, Xoconostle-Cázares B, Toscano-Morales R, Arturo Ramirez-Ortega F, Luis Cabrera-Ponce J, Ruiz-Medrano R. Characterization of the pumpkin translationally-controlled tumor protein CMTCTP. Plant Signal Behav. 2013;8(12):e26477.

30. Gupta M, Yoshioka H, Ohnishi K, Mizumoto H, Hikichi Y, Kiba A. A translationally controlled tumor protein negatively regulates the hypersensitive response in Nicotiana benthamiana. Plant Cell Physiol. 2013;54(8):1403-14.

31. Wang F, Shang $Y$, Yang $L$, Zhu C. Comparative proteomic study and functional analysis of translationally controlled tumor protein in rice roots under $\mathrm{Hg}^{2+}$ stress. J Environ Sci. 2012;24(12):2149-58.

32. Hiei $Y$, Ohta S, Komari T, Kumashiro T. Efficient transformation of rice (Oryza sativa L.) mediated by Agrobacterium and sequence analysis of the boundaries of the T-DNA. Plant J. 1994;6(2):271-82.

33. Dayhoff MO, Schwartz RM, Orcutt BC. A model of evolutionary change in proteins. In: Dayhoff MO, editor. Atlas of Protein Sequence and Structure, vol. 5(Suppl 3). Washington, DC: National Biomedical Research Foundation; 1978. p. 345-52.

34. Quevillon E, Silventoinen V, Pillai S, Harte N, Mulder N, Apweiler R, et al. InterProScan: protein domains identifier. Nucleic Acids Res. 2005:33(W):W116-20

35. Hinojosa-Moya J, Xoconostle-Cázares B, Piedra-lbarra E, Méndez-Tenorio A, Lucas WJ, Ruiz-Medrano R. Phylogenetic and structural analysis of translationally controlled tumor proteins. J Mol Evol. 2008;66(5):472-83.
36. Jeon JS, Lee $\mathrm{S}$, Jung $\mathrm{KH}$, Jun $\mathrm{SH}$, Jeong $\mathrm{DH}$, Lee J, et al. T-DNA insertiona mutagenesis for functional genomics in rice. Plant J. 2000;22(6):561-70.

37. An S, Park S, Jeong DH, Lee DY, Kang HG, Yu JH, et al. Generation and analysis of end sequence database for T-DNA tagging lines in rice. Plant Physiol. 2003;133(4):2040-7.

38. Cobbett C, Goldsbrough P. Phytochelatins and metallothioneins: roles in heavy metal detoxification and homeostasis. Annu Rev Plant Biol. 2002;53:159-82.

39. Park J, Song WY, Ko D, Eom Y, Hansen TH, Schiller M, et al. The phytochelatin transporters AtABCC1 and AtABCC2 mediate tolerance to cadmium and mercury. Plant J. 2012;69(2):278-88.

40. Chen YA, Chi WC, Huang TL, Lin CY, Quynh Nguyeh TT, Hsiung YC, et al. Mercury-induced biochemical and proteomic changes in rice roots. Plant Physiol Biochem. 2012;55:23-32.

41. Sahu GK, Upadhyay S, Sahoo BB. Mercury induced phytotoxicity and oxidative stress in wheat (Triticum aestivum L.) plants. Physiol Mol Biol Plants. 2012;18(1):21-31.

42. Yang $Y$, Yang F, Xiong Z, Yan $Y$, Wang $X$, Nishino $M$, et al. An N-terminal region of translationally controlled tumor protein is required for its antiapoptotic activity. Oncogene. 2005;24(30):4778-88.

43. Yarm FR. Plk phosphorylation regulates the microtubule-stabilizing protein TCTP. Mol Cell Biol. 2002;22(17):6209-21.

44. Jung J, Kim M, Kim MJ, Kim J, Moon J, Lim JS, et al. Translationally controlled tumor protein interacts with the third cytoplasmic domain of $\mathrm{Na}$, K-ATPase alpha subunit and inhibits the pump activity in HeLa cells. J Biol Chem. 2004;279(48):49868-75.

45. Kim M, Jung $Y$, Lee K, Kim C. Identification of the calcium binding sites in translationally controlled tumor protein. Arch Pharm Res. 2000;23(6):633-6.

46. Yoon T, Jung J, Kim M, Lee KM, Choi EC, Lee K. Identification of the selfinteraction of rat TCTP/lgE-dependent histamine-releasing factor using yeast two-hybrid system. Arch Biochem Biophys. 2000;384(2):379-82.

47. Maeng J, Kim HY, Shin DH, Lee K. Transduction of translationally controlled tumor protein employing TCTP-derived protein transduction domain. Anal Biochem. 2013;435(1):47-53.

48. Hsu YC, Chern JJ, Cai Y, Liu M, Choi KW. Drosophila TCTP is essential for growth and proliferation through regulation of dRheb GTPase. Nature. 2007:445(7129):785-8.

49. Diraison F, Hayward K, Sanders KL, Brozzi F, Lajus S, Hancock J, et al. Translationally controlled tumour protein (TCTP) is a novel glucose-regulated protein that is important for survival of pancreatic beta cells. Diabetologia. 2011;54(2):368-79.

50. Henquet M, Lehle L, Schreuder M, Rouwendal G, Molthoff J, Helsper J, et al. Identification of the gene encoding the alpha1,3-mannosyltransferase (ALG3) in Arabidopsis and characterization of downstream n-glycan processing. Plant Cell. 2008;20(6):1652-64.

51. Tan H, Liang W, Hu J, Zhang D. MTR1 encodes a secretory fasciclin glycoprotein required for male reproductive development in rice. Dev Cell. 2012;22(6):1127-37.

52. Sparkes IA, Runions J, Kearns A, Hawes C. Rapid, transient expression of fluorescent fusion proteins in tobacco plants and generation of stably transformed plants. Nat Protoc. 2006;1(4):2019-25.

53. Sambrook J, Russell DW. Molecular Cloning: A Laboratory Manual. 3rd ed Cold Spring Harbor: Cold Spring Harbor Laboratory Press; 2001.

54. Chen R, Zhao X, Shao Z, Wei Z, Wang Y, Zhu L, et al. Rice UDP-glucose pyrophosphorylase 1 is essential for pollen callose deposition and its cosuppression results in a new type of thermosensitive genic male sterility. Plant Cell. 2007;19(3):847-61.

55. Wesley SV, Helliwell CA, Smith NA, Wang MB, Rouse DT, Liu Q, et al. Construct design for efficient, effective and high-throughput gene silencing in plants. Plant J. 2001;27(6):581-90.

56. Xin Z, Chen J. A high throughput DNA extraction method with high yield and quality. Plant Methods. 2012;8(1):26

57. Southern EM. Detection of specific sequences among DNA fragments separated by gel electrophoresis. J Mol Biol. 1975;98(3):503-17.

58. Jefferson RA, Kavanagh T, Bevan MW. GUS fusions: $\beta$-glucuronidase as a sensitive and versatile gene fusion marker in higher plants. EMBO J. 1987;6(13):3901-7.

59. Schmittgen TD, Livak KJ. Analyzing real-time PCR data by the comparative C(T) method. Nat Protoc. 2008;3(6):1101-8.

60. Yamaji N, Huang CF, Nagao S, Yano M, Sato Y, Nagamura Y, et al. A zinc finger transcription factor ART1 regulates multiple genes implicated in aluminum tolerance in rice. Plant Cell. 2009;21(10):3339-49. 
61. Fujita M, Fujita Y, Maruyama K, Seki M, Hiratsu K, Ohme-Takagi M, et al. A dehydration-induced NAC protein, RD26, is involved in a novel ABA-dependent stress-signaling pathway. Plant J. 2004;39(6):863-76.

62. Xiong $L$, Yang $Y$. Disease resistance and abiotic stress tolerance in rice are inversely modulated by an abscisic acid-inducible mitogen-activated protein kinase. Plant Cell. 2003;15(3):745-59.

63. Saijo Y, Hata S, Kyozuka J, Shimamoto K, Izui K. Over-expression of a single $\mathrm{Ca}^{2+}$-dependent protein kinase confers both cold and salt/drought tolerance on rice plants. Plant J. 2000;23(3):319-27.

64. Jang IC, Oh SJ, Seo JS, Choi WB, Song SI, Kim CH, et al. Expression of a bifunctional fusion of the Escherichia coli genes for trehalose-6-phosphate synthase and trehalose-6-phosphate phosphatase in transgenic rice plants increases trehalose accumulation and abiotic stress tolerance without stunting growth. Plant Physiol. 2003;131(2):516-24.

65. Ortega-Villasante C, Hernández LE, Rellán-Alvarez R, Del Campo FF, Carpena-Ruiz RO. Rapid alteration of cellular redox homeostasis upon exposure to cadmium and mercury in alfalfa seedlings. New Phytol. 2007;176(1):96-107.

66. Carrasco-Gil S, Alvarez-Fernández A, Sobrino-Plata J, Millán R, Carpena-Ruiz $\mathrm{RO}$, Leduc $\mathrm{DL}$, et al. Complexation of $\mathrm{Hg}$ with phytochelatins is important for plant Hg tolerance. Plant Cell Environ. 2011;34(5):778-91.

67. Li Q, Yu B, Gao Y, Dai AH, Bai JG. Cinnamic acid pretreatment mitigates chilling stress of cucumber leaves through altering antioxidant enzyme activity. J Plant Physiol. 2011;168(9):927-34.

68. Suharsono U, Fujisawa Y, Kawasaki T, Iwasaki Y, Satoh H, Shimamoto K. The heterotrimeric $\mathrm{G}$ protein alpha subunit acts upstream of the small GTPase Rac in disease resistance of rice. Proc Natl Acad Sci U S A. 2002;99(20):13307-12

69. Xue T, Li X, Zhu W, Wu C, Yang G, Zheng C. Cotton metallothionein GhMT3a, a reactive oxygen species scavenger, increased tolerance against abiotic stress in transgenic tobacco and yeast. J Exp Bot. 2009;60(1):339-49.

70. Zhou Q, Yu Q, Wang Z, Pan Y, Lv W, Zhu L, et al. Knockdown of GDCH gene reveals reactive oxygen species-induced leaf senescence in rice. Plant Cell Environ. 2013;36(8):1476-89.

71. Tamura K, Peterson D, Peterson N, Stecher G, Nei M, Kumar S. MEGA5 Molecular Evolutionary Genetics Analysis using Maximum Likelihood, Evolutionary Distance, and Maximum Parsimony Methods. Mol Biol Evol. 2011;28(10):2731-9

72. Zhang H, Liang W, Yang X, Luo X, Jiang N, Ma H, et al. Carbon starved anther encodes a MYB domain protein that regulates sugar partitioning required for rice pollen development. Plant Cell. 2010;22(3):672-89.

73. Arnold K, Borfdoli L, Kopp J, Schwede T. The SWISS-MODEL workspace: A webbased environment for protein structure homology modelling. Bioinformatics. 2006;22(2):195-201.

74. Tang QY, Zhang CX. Data Processing System (DPS) software with experimental design, statistical analysis and data mining developed for use in entomological research. Insect Sci. 2013;20(2):254-60.

\section{Submit your next manuscript to BioMed Central and take full advantage of:}

- Convenient online submission

- Thorough peer review

- No space constraints or color figure charges

- Immediate publication on acceptance

- Inclusion in PubMed, CAS, Scopus and Google Scholar

- Research which is freely available for redistribution 